\title{
Rapid Fabrication of Periodic Patterns on Poly(styrene-co-acrylonitrile) Surfaces Using Direct Laser Interference Patterning
}

\author{
Martin F. Broglia, ${ }^{1,2}$ Diego F. Acevedo, ${ }^{1,2}$ Denise Langheinrich,,4 \\ Heidi R. Perez-Hernandez, ${ }^{3,4}$ Cesar A. Barbero, ${ }^{1}$ and Andrés F. Lasagni ${ }^{3,4}$ \\ ${ }^{1}$ Department of Chemistry, National University of Río Cuarto, Route 36, km 601, 5800 Rio Cuarto, Argentina \\ ${ }^{2}$ Faculty of Engineering, National University of Río Cuarto, Route 36, km 601, 5800 Rio Cuarto, Argentina \\ ${ }^{3}$ Fraunhofer Institute for Material and Beam Technology, Winterbergstraße 28, 01277 Dresden, Germany \\ ${ }^{4}$ Technische Universität Dresden, Institute of Manufacturing Technology, George-Bähr-Straße 3c, 01069 Dresden, Germany
}

Correspondence should be addressed to Diego F. Acevedo; dacevedo@ing.unrc.edu.ar and Andrés F. Lasagni; andres-fabian.lasagni@iws.fraunhofer.de

Received 1 January 2015; Accepted 12 February 2015

Academic Editor: Angel Concheiro

Copyright (C) 2015 Martin F. Broglia et al. This is an open access article distributed under the Creative Commons Attribution License, which permits unrestricted use, distribution, and reproduction in any medium, provided the original work is properly cited.

\begin{abstract}
Periodic microstructures in styrene-acrylonitrile (SAN) copolymers are fabricated by two-beam direct laser interference patterning using a nanosecond pulsed laser operating at a wavelength of $266 \mathrm{~nm}$. The SAN copolymers are synthesized using different molar ratios (styrene to acrylonitrile) by a free radical polymerization process. The chemical composition of the copolymers and their properties are determined using Fourier transformed infrared spectroscopy (FTIR) and differential scanning calorimetry (DSC). Depending on the composition of the irradiated copolymer films, with weight ratios ranging from 58 to $96.5 \%$ of styrene to acrylonitrile, different ablation behaviors are observed. The laser fluence necessary to locally ablate the copolymer is found to be dependent on the copolymer composition. Unlike other dielectric polymers, the laser irradiation produced both direct ablation of the irradiated material and collapse of the surface. It is shown that, by varying the laser fluence and the copolymer composition, the surface structure can be changed from a periodic pattern with a swelled topography to an ablated-like structure. The number of holes does not depend monotonically on the amount of PS or PAN units but shows a more complex behavior which depends on the copolymer composition and the laser fluence.
\end{abstract}

\section{Introduction}

Styrene-acrylonitrile (SAN) copolymers are widely used in place of polystyrene owing to their greater thermal resistance. Furthermore, they are optically clear and exhibit good rigidity as well as a high chemical resistance and can be easily processed $[1,2]$. Typically, SAN copolymers are employed to construct automotive parts (e.g., battery cases) and also for kitchenware, appliances, furniture, and medical supplies [3]. In addition, in applications requiring special structural properties, SANs are often used in polymer blends mixed with polyurethanes, polyamides, and polymethacrylates [4-6]. Polyacrylonitrile surfaces can be easily modified by reaction of the nitrile group with hydroxide ions [7]. In that way, the wetting properties changed and the carboxyl groups on the surface can be used to conjugate with bioactive molecules [8].

However, not only the chemistry but also the topography of the surface material defines its use. The topographic effect can be achieved by fabricating microstructured surfaces with periodic surface topographies. For instance, surface related properties like wetting behavior, friction, and adhesion of cells and/or bacteria, besides others have been proved to be strongly dependent on the surface topography [9-13]. The fabrication of these micro- and nanostructured surfaces has been realized using different methods which normally require multiple fabrication steps and/or special molds or 
masks featured with the desired structure, such as optical lithography, microcontact printing, and hot embossing. Furthermore, processes like chemical, electrochemical, or physical etching (such as reactive ion and plasma etching) also require hazardous chemicals that are subsequently employed to transfer the pattern from the photoresist into the surface of the material.

An alternative to chemical and physical methods is laser based processing technologies. Direct laser writing (DLW) has been used to directly fabricate microstructures on different kinds of materials mainly based on photochemical or photothermal ablation processes. However, the resolution in DLW is controlled by the laser wavelength as well as the numerical aperture of the used optic and therefore is normally limited to feature sizes up to 5 to $10 \mu \mathrm{m}$. Furthermore, long processing times are required especially if large areas $\left(\mathrm{cm}^{2}\right.$ to $\left.\mathrm{m}^{2}\right)$ have to be patterned. An alternative to DLW is direct laser interference patterning (DLIP). This technique has shown to be useful to fabricate surface periodic structures with feature sizes even below the diffraction limit with the additional advantage that neither masks nor molds are necessary to obtain the final structure. In DLIP, an interference pattern is created by overlapping two or more coherent laser beams, which can be transferred directly onto the material surface if enough energy per unit of area is applied. Due to the high laser intensity at the interference maxima positions, bulk materials (e.g., polymers, metals, ceramics, and coatings) are patterned by photoinduced ablation processes [14]. The geometry and size (period) of the interference pattern are controlled by the laser wavelength $(\lambda)$, the incidence angle of the individual beams $(\theta)$, and the number of the utilized laser beams [15]. Therefore, the control of the optical configuration and the laser processing parameters (laser power and number of laser pulses) permit perfectly creating a well-defined surface topography with controlled topographical parameters (structure depth and period).

In the present work, we report the fabrication of periodic surface structures on styrene-acrylonitrile (SAN) copolymers using DLIP. The composition of the synthetized styrene-coacrylonitrile copolymers and the relation of the molar ratios in the feed and in the final material were determined using FTIR spectroscopy. Subsequently, the samples were patterned applying the DLIP method using ultraviolet laser light. The influence of the chemical composition of the copolymer and the laser processing parameters on the laser ablation mechanism and therefore on the surface morphology was investigated.

\section{Materials and Methods}

2.1. Materials. Styrene-acrylonitrile (SAN) copolymers were synthesized in glass ampoules sealed with rubber septa in bulk $\left(3 \mathrm{~mol} \mathrm{~L}^{-1}\right)$ using benzoyl peroxide as initiator. Acrylonitrile and styrene monomer were used as received. Dissolved oxygen was removed from the reaction solution by nitrogen purging for $30 \mathrm{~min}$ prior to immersion in a water bath at $60^{\circ} \mathrm{C}$. Subsequently, the ampoule was removed from the water bath, and the reaction was stopped with
TABLE 1: Compositions of the feeds (styrene $=S$; acrylonitrile $=A N)$ used to synthesize the SAN copolymer films.

\begin{tabular}{lcc}
\hline $\begin{array}{l}\text { Mass relation in } \\
\text { feed } \\
\text { [gr S/gr. AN] }\end{array}$ & $\begin{array}{c}\text { Mole relation in } \\
\text { feed } \\
\text { [mol S/mol. AN }]\end{array}$ & $\begin{array}{c}\text { Denomination } \\
\text { of the } \\
\text { copolymer }\end{array}$ \\
\hline 0.667 & 0.253 & SAN $(40: 60)$ \\
1.50 & 0.434 & SAN $(60: 40)$ \\
2.25 & 0.535 & SAN $(70: 30)$ \\
4.07 & 0.675 & SAN $(80: 20)$ \\
\hline
\end{tabular}

$0.5 \mathrm{~mL}$ of a $10 \mathrm{wt} \%$ solution of hydroquinone. The solid was washed several times with chloroform in order to remove the remaining monomer. Afterwards, dimethylformamide (DMF) was used to dissolve the copolymer. The films of the copolymer were prepared by evaporation of $5 \% \mathrm{w} / \mathrm{v}$ solution of SAN copolymer in DMF. All monomers and chemicals were purchased from Sigma-Aldrich (St. Louis, USA). The different compositions of the feed used can be seen in Table 1 .

\subsection{Methods}

2.2.1. Polymer Characterization. Fourier transformed infrared (FTIR) spectra of the nonstructured copolymers were performed using a Nicolet Impact 410 spectrometer. The spectrum was recorded between $500 \mathrm{~cm}^{-1}$ and $6000 \mathrm{~cm}^{-1}$. Differential scanning calorimetry (DSC) measurements were conducted using a TA Instruments DSC 2010 under nitrogen flow. Sealed aluminum capsules were quickly cooled inside the differential scanning calorimeter chamber to $20^{\circ} \mathrm{C}$. After several minutes, the sample holder assembly was heated at a rate of $10^{\circ} \mathrm{C} \mathrm{min}^{-1}$ from 20 to $250^{\circ} \mathrm{C}$.

2.2.2. Laser Interference Experiments. A high-power pulsed Nd:YAG (Spectra Physics, Quanta-Ray Pro 290) with a wavelength of $266 \mathrm{~nm}$, frequency of $10 \mathrm{~Hz}$, and pulse duration of $10 \mathrm{~ns}$ was used for all interference experiments. A scheme of the experimental set-up has already been shown elsewhere [14]. The laser beams are guided to overlap on the samples surface by using different optical elements including mirrors, beam splitters, and lenses. The energy density was varied between $500 \mathrm{~mJ} \mathrm{~cm}^{-2}$ and $1000 \mathrm{~mJ} \mathrm{~cm}^{-2}$. Only one laser pulse was used in each experiment. Line-like patterns with a spatial period of $5 \mu \mathrm{m}$ were fabricated on all samples.

2.2.3. Surface Characterization. All samples were imaged with a high-resolution scanning electron microscope (SEM) at $5 \mathrm{kV}$ acceleration voltage. The structure period was characterized using a confocal microscope (Leica DCM 3D). The pore form factor was evaluated by image processing of the SEM data [16], using ImageJ software [17].

2.2.4. Quantitative Measurement of the Holes Area. The quantitative measurement of the hole area was made using ImageJ software. The SEM images were opened with this software, and then they were transformed in an 8-bit image. The scale is calibrated with the scale bar shown in the SEM image. Then 


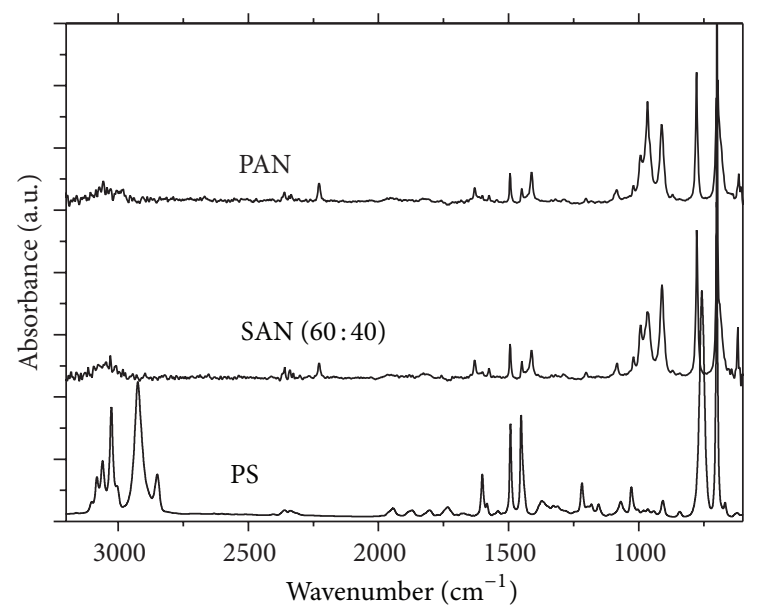

FIgURE 1: FTIR spectra of PS, PAN, and SAN copolymer $(60: 40)$.

TABLE 2: FTIR spectroscopy absorption of the more relevant bands of polymers.

\begin{tabular}{llc}
\hline $\begin{array}{l}\text { Wavenumber } \\
{\left[\mathrm{cm}^{-1}\right]}\end{array}$ & Assignment & Polymer \\
\hline 907 & $\begin{array}{l}\text { Aliphatic C-H wag band } \\
\text { Phenyl ring in plane C-H } \\
\text { bending vibration band (I) } \\
1028\end{array}$ & PAN, PS, SAN \\
1071 & $\begin{array}{l}\text { Phenyl ring in plane C-H } \\
\text { bending vibration band (II) } \\
\text { Quadrant stretching of the } \\
\text { phenyl ring C=C } \\
\text { CEN bond stretching }\end{array}$ & PS, SAN \\
2228 & & PS, SAN \\
\hline
\end{tabular}

using the utility measure of the software the black round-like areas surrounded by white borders were quantified. Those areas were assumed to correspond to the holes. A table of distribution of holes areas is elaborated and made into and histogram which is fitted with a Gaussian distribution (see Figure 4(a)). The latter procedures are made using Origin 7.0 software (Microcal). The area value for the maximum is then plotted as a function of the copolymer feed ratio.

\section{Results and Discussion}

Figure 1 shows the infrared spectra of the homopolymer of styrene (PS) and acrylonitrile (PAN), as well as the spectrum of a copolymer. The more relevant bands are summarized in Table 2. The spectra of PS and PAN show all characteristic bands of each homopolymer while the copolymer's spectrum (in this case SAN 60:40) shows the bands corresponding to both monomeric units. This result indicates that the chemical structure of the synthesized compound corresponds to both styrene and acrylonitrile monomer units, showing that the copolymerization was effective.

In order to determinate the copolymer composition, the fraction of styrene to acrylonitrile units was determined using the method proposed by Takeuchi, by measuring the ratio of the near infrared bands at $1.67 \mu \mathrm{m}\left(5970 \mathrm{~cm}^{-1}\right)$ to $1.910 \mu \mathrm{m}\left(5235 \mathrm{~cm}^{-1}\right)$ [18]. The band corresponding to $1.67 \mu \mathrm{m}$ is assigned as an overtone of phenyl C-H c.a. $3000 \mathrm{~cm}^{-1}\left(3000 \mathrm{~cm}^{-1} \times 2=6000 \mathrm{~cm}^{-1}=1.67 \mu \mathrm{m}\right)$ being its absorbance directly proportional to both the styrene content of the copolymer and the thickness of the film. The bands at 10 1.910 and $1.952 \mu \mathrm{m}$ are combination tones of acrylonitrile and are assigned as, respectively, $v(\mathrm{CN})+v\left(\mathrm{CH}_{3}\right)(2237+2940$ $\left.=5177 \mathrm{~cm}^{-1}=1.932 \mu \mathrm{m}\right)$ and $v(\mathrm{CN})+v\left(\mathrm{CH}_{3}\right)(2237+2870$ $\left.=5107 \mathrm{~cm}^{-1}=1.958 \mu \mathrm{m}\right)$. Figure 2(a) shows the near infrared spectra of the synthesized copolymers in a range of $2.1 \mu \mathrm{m}$ and $1.67 \mu \mathrm{m}$, while Figure 2(b) shows the relationship between the feed ratio and copolymer ratio for styrene using the model proposed by Takeuchi et al. [18]. The final composition of the copolymer was later obtained measuring the absorption ratio of solid synthetized material, indicating that the weight composition of styrene varied between 58 and $96.5 \%$ w/w.

As it can be observed in Figure 2, increasing the styrene ratio in the feed results in an increase of the styrene units in the copolymer. The amount of styrene in the copolymer backbone was always higher than in the feed. This behavior can be explained since the styrene units are more reactive than acrylonitrile ones [19].

In Figure 2(b), the glass transition temperatures $\left(T_{g}\right)$ of each synthesized copolymer, determined using differential scanning calorimetry (DSC) technique, are shown. As can be observed, the $T_{g}$ values for all SAN copolymers are ranging from $70^{\circ} \mathrm{C}$ to $78^{\circ} \mathrm{C}$ [20]. These $T_{g}$ values are below the measured values of the pure components, PS $\left(T_{g}=80^{\circ} \mathrm{C}\right)$ and PAN $\left(T_{g}=93^{\circ} \mathrm{C}\right)$. This behavior has been also observed in other copolymers since random copolymers tend to have intermediate chain stiffness and the macromolecules present interchain attraction $[21,22]$. Moreover, the DSC experiments of the synthetized materials show a single $T_{g}$ value (not shown) indicating the presence of a copolymer, ensuring that the materials are not just a mixture of the two homopolymers (PA and PAN). Furthermore, the $T_{g}$ of the copolymers is low enough to allow for softening of the material upon laser heating.

After that, the synthetized copolymers were irradiated using two-beam DLIP with a wavelength of $266 \mathrm{~nm}$. The angle between the laser beams was set to $1.52^{\circ}$, obtaining a line-like interference pattern with a special period of $5.0 \mu \mathrm{m}$. The surface topography of the fabricated periodic structures in the different copolymers was investigated. Figure 3 shows scanning electron microscope (SEM) images of the SAN copolymers $(80: 20 ; 60: 40 ; 40: 60$, feed composition styrene/acrylonitrile) irradiated using different laser fluences $\left(610\right.$ and $972 \mathrm{~mJ} \mathrm{~cm}^{-2}$ ). The images show that the material remains unchanged at the interference minima positions for all of the experiences. Qualitatively, it can be seen that the amount and size of holes depend on the copolymer composition and the laser fluence.

Previous work has shown that ablation of polystyrene occurs without generation of gaseous products [12]. On the other hand, Nishio and colleagues [23] reported that structural changes on nitrile groups in polyacrylonitrile, such as elimination and cyclization reaction, occur when it is 


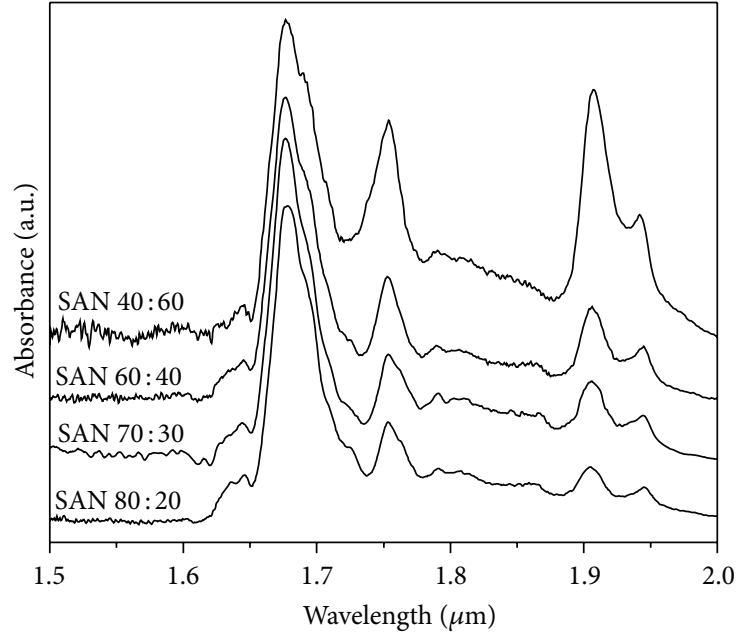

(a)

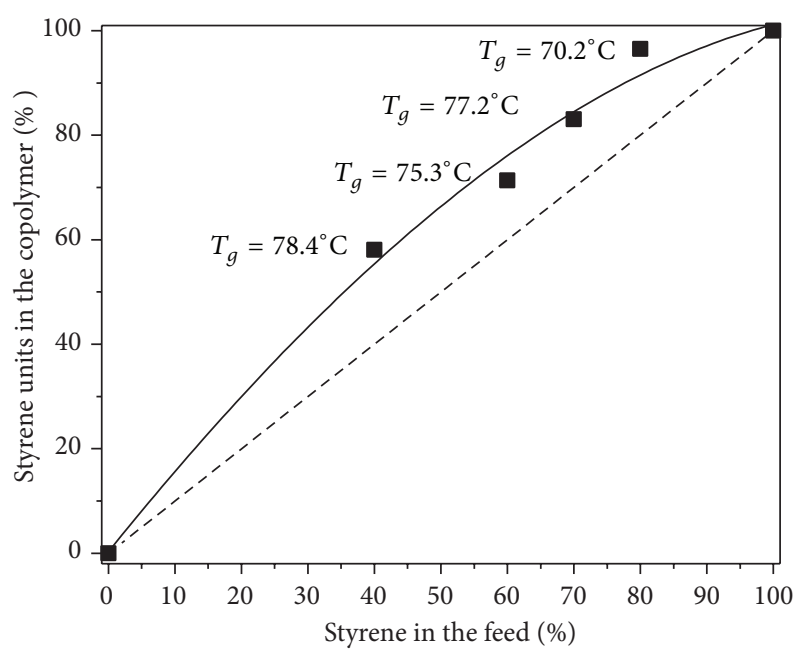

(b)

Figure 2: (a) FTIR spectra of SAN copolymers. (b) Relationship between the \% of styrene in the feed and the \% of styrene units in the copolymer. Next to each copolymer point, the value of measured glass transition temperature is depicted. Full line is a polynomial fitting of the data. Dashed line represents the relationship for equal reactivity between acrylonitrile and styrene.

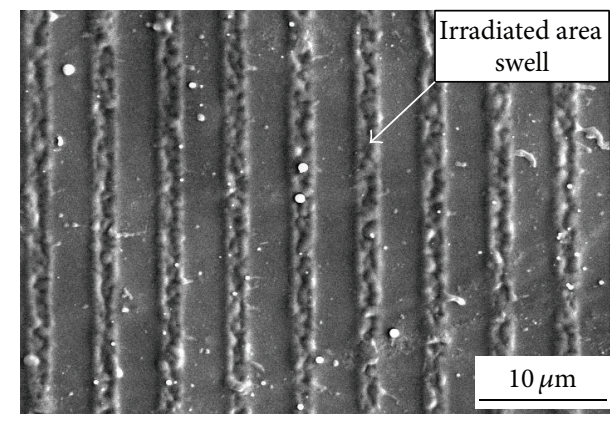

(a)

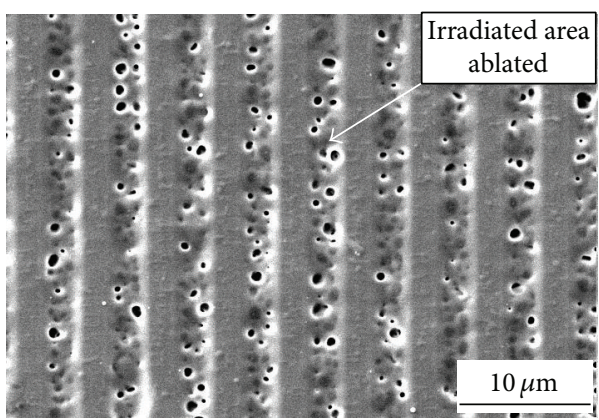

(c)

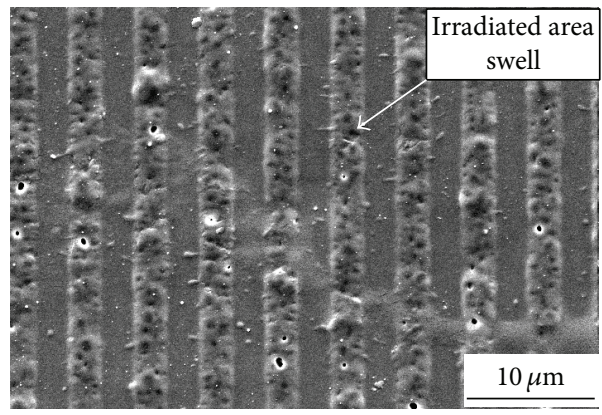

(e)

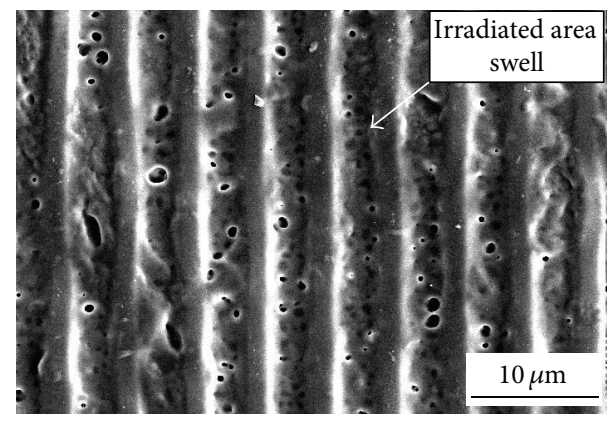

(b)

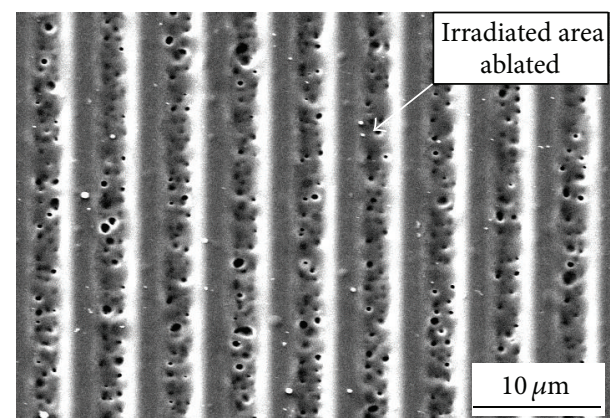

(d)

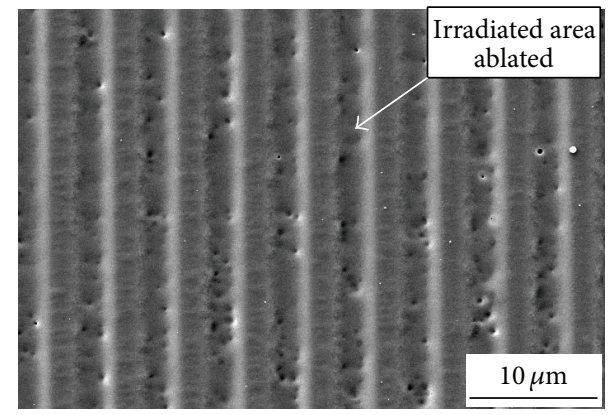

(f)

FIGURE 3: Line-like patterns produced on different SAN copolymers samples at different laser fluences: (a) $40: 60$, (c) $60: 40$, and (e) $80: 20$ (laser fluence: $610 \mathrm{~mJ} \mathrm{~cm}^{-2}$ ) and (b) $40: 60$, (d) $60: 40$, and (f) $80: 20$ (laser fluence $=972 \mathrm{~mJ} \mathrm{~cm}^{-2}$ ). In all cases the period was $5 \mu \mathrm{m}$ and the SAN samples were irradiated with laser radiation of $266 \mathrm{~nm}(\sim 10 \mathrm{~ns}$ pulse width). 


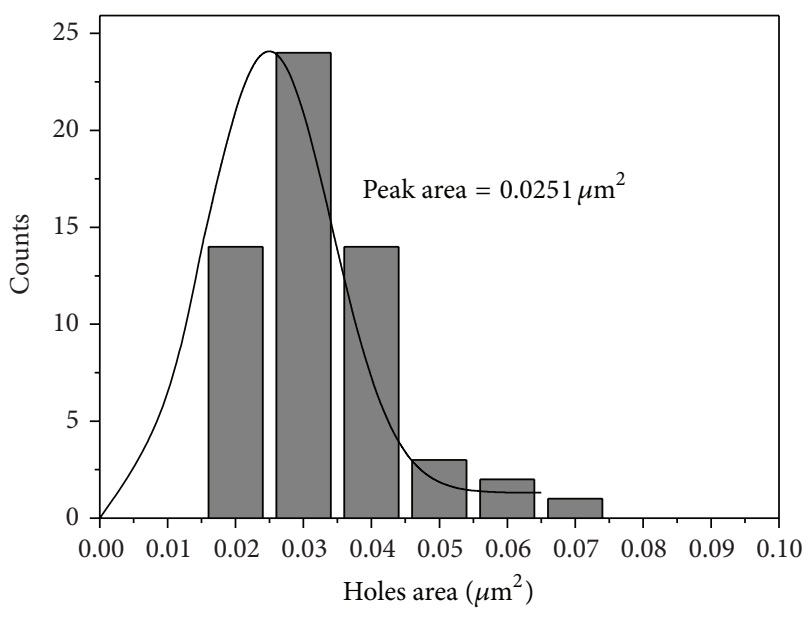

(a)

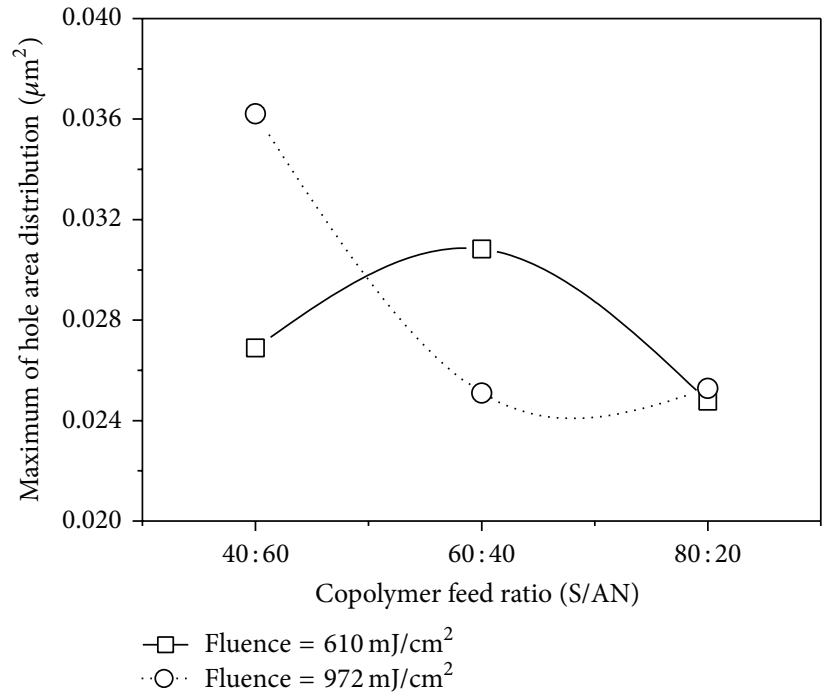

(b)

Figure 4: (a) Typical histogram (calculated from SEM image depicted in Figure 3(c)) of the holes areas, together with the distribution of holes areas in the SEM image. (b) Dependence of the maximum of hole area distribution obtained from the histograms like the one shown in Figure 4(a) on the copolymer feed ratio, at different fluences (stated in the figure).

irradiated with UV laser light. Cyclization reactions and elimination of nitrogen atoms are induced more extensively when the excess energy increases with increasing laser fluence, similar to carbon fiber formation by pyrolysis of PAN [2426]. Therefore, the elimination of nitrile groups is observed for PAN when it is irradiated with UV laser. The energy of the laser beam is enough to break the $\mathrm{C}-\mathrm{C}$ bond between the primary chain and nitrile groups, forming gaseous products $[27,28]$. A similar gas formation process has been reported for poly(styrene-co-methyl methacrylate) [15, 29]. Moreover, it is possible to observe that the swelling profiles and heights decrease when the fluence tends to increase, probably because the loss of material by ablation into gas is more important at this high fluences. The same behavior has been reported and simulated by Lazare et al. [30]. Due to the high absorption coefficient of the styrene monomer at $266 \mathrm{~nm}$ [31], the styrene units in the copolymer backbone produce a synergetic effect enhancing absorption and generating heat, allowing in this manner the decomposition of acrylonitrile units and thus producing bubbles [32].

A more quantitative assessment of the degree of hole formation can be made by image analysis of the SEM micrographs. The area of the holes follows a Gaussian distribution (Figure 4(a)). The maximum value for the holes area depends on both the copolymer composition and the laser fluence used (Figure 4(b)). On one hand, the copolymer with less acrylonitrile units $(80: 20$ feed ratio) shows a smaller degree of hole formation, likely due to the absence of the gas forming groups (nitrile). In agreement with that model, at a higher laser fluence $\left(972 \mathrm{~mJ} \mathrm{~cm}^{-2}\right)$, the size of the holes decreases clearly when the amount of acrylonitrile units in the copolymer diminishes (Figure 4(b)) [30].

On the other hand, at lower laser fluences $\left(610 \mathrm{~mJ} \mathrm{~cm}^{-2}\right)$ a more complex process is operative. At smaller amount of styrene units in the copolymer, the acrylonitrile absorption is not enough for maximum degree of holes formation. This only occurs at an intermediate composition $(60: 40)$ value when there are enough styrene units for light absorption and acrylonitrile units for gas formation. In copolymers with higher amounts of styrene units $(80: 20)$, the limited amount of acrylonitrile units makes the hole formation by gas release become small and independent of the laser fluence.

An advantage of SAN copolymers over pure PS is that chemical composition of the copolymer surface can be easily modified by reactions on the nitrile group [33]. Treatment with concentrated sodium hydroxide produces the hydrolysis of the nitrile groups to give carboxylate.

\section{Conclusions}

We have shown the possibility to fabricate periodic microstructures in styrene-acrylonitrile copolymers using direct laser interference patterning operating at a wavelength of $266 \mathrm{~nm}$. The obtained complex surface architectures result from the synergetic properties of the individual components. We have also shown that by varying the laser fluence and the copolymer composition the surface structure can be changed from a periodic pattern with a swelled topography to an ablated-like structure, similar to the ablation behavior of other homopolymers (e.g., polystyrene, polycarbonate, etc.). The ablation processes in the copolymers appear to be related to the formation of pores by gaseous products generated by decomposition of the acrylonitrile monomer unit when the laser light interacts with the sample. Finally, the micromodification of the SAN copolymers topography seems to be adequate for changing surface properties. In addition, the presence of acrylonitrile units makes it possible to chemically functionalize the surface allowing the attachment of bioactive molecules. 


\section{Conflict of Interests}

The authors declare that there is no conflict of interests regarding the publication of this paper.

\section{Acknowledgments}

This work was supported by FONCYT, CONICET, SECYTUNRC, and the International Bureau of the Federal Ministry of Education and Research, Germany, and the Ministry of Science and Technology, Argentina (bilateral cooperative project in education and research (Project no. ARG 09/10)). The authors wish to thank the EU (IRSES project "SUMA2Network," Project no. 318903) for the financial support for the scientist's mobility.

\section{References}

[1] G. E. McKee, A. Kistenmacher, H. Goerrissen, and M. Breulmann, "Chapter 16. Synthesis, properties and applications of acrylonitrile-styrene-acrylate polymers," in Modern Styrenic Polymers: Polystyrenes and Styrenic Copolymers, J. Scheirs and D. B. Priddy, Eds., John Wiley \& Sons, New York, NY, USA, 2003.

[2] G. P. Ziemba, "Acrylonitrile-styrene copolymers," in Encyclopedia of Polymer Science and Technology, H. F. Mark, N. G. Gaylord, and N. M. Bikales, Eds., vol. 1, pp. 425-435, Interscience, New York, NY, USA, 1964.

[3] J. Maul, B. G. Frushour, J. R. Kontoff, H. Eichenauer, K. H. Ott, and C. Schade, "Polystyrene and styrene copolymers," in Ullmann's Encyclopedia of Industrial Chemistry, B. Elvers, S. Hawkins, and W. Russey, Eds., Wiley-VCH, Weinheim, Germany, 2003.

[4] M. Ulcnik-Krump, R. Stadler, and T. Malavasic, "Investigation of properties of compatibilized TPU/SAN blends," Macromolecular Symposia, vol. 149, no. 1, pp. 131-136, 2000.

[5] P. Pötschke and D. R. Paul, "Detection of co-continuous structures in SAN/PA6 blends by different methods," Macromolecular Symposia, vol. 198, no. 1, pp. 69-82, 2003.

[6] E. M. Woo, T. K. Mandal, and L. L. Chang, "Window of acrylonitrile content for miscibility in blends comprising poly(styrene-co-acrylonitrile)s and poly(benzyl methacrylate)," Macromolecules, vol. 33, no. 11, pp. 4186-4192, 2000.

[7] H. R. Lohokare, S. C. Kumbharkar, Y. S. Bhole, and U. K. Kharul, "Surface modification of polyacrylonitrile based ultrafiltration membrane," Journal of Applied Polymer Science, vol. 101, no. 6, pp. 4378-4385, 2006.

[8] R. Kumar, I. Roy, T. Y. Ohulchanskyy et al., "Covalently dye-linked, surface-controlled, and bioconjugated organically modified silica nanoparticles as targeted probes for optical imaging," ACS Nano, vol. 2, no. 3, pp. 449-456, 2008.

[9] F. Yu, P. Li, H. Shen et al., "Laser interference lithography as a new and efficient technique for micropatterning of biopolymer surface," Biomaterials, vol. 26, no. 15, pp. 2307-2312, 2005.

[10] F. Yu, F. Mücklich, P. Li et al., "In vitro cell response to a polymer surface micropatterned by laser interference lithography," Biomacromolecules, vol. 6, no. 3, pp. 1160-1167, 2005.

[11] D. Yuan, A. Lasagni, P. Shao, and S. Das, "Rapid prototyping of microstructured hydrogels via laser direct-write and laser interference photopolymerisation," Virtual and Physical Prototyping, vol. 3, no. 4, pp. 221-229, 2008.
[12] A. S. A. Ramazani, S. A. Mousavi, E. Seyedjafari et al., "Corrigendum to 'Polycarbonate surface cell's adhesion examination after Nd:YAG laser irradiation,' Materials Science and Engineering C, vol. 29, pp. 1491-1497, 2009.

[13] W. Lee, M.-K. Jin, W.-C. Yoo, and J.-K. Lee, "Nanostructuring of a polymeric substrate with well-defined nanometer-scale topography and tailored surface wettability," Langmuir, vol. 20, no. 18, pp. 7665-7669, 2004.

[14] A. F. Lasagni, D. F. Acevedo, C. A. Barbero, and F. Mücklich, "One-step production of organized surface architectures on polymeric materials by direct laser interference patterning," Advanced Engineering Materials, vol. 9, no. 1-2, pp. 99-104, 2007.

[15] A. F. Lasagni, D. F. Acevedo, C. A. Barbero, and F. Mücklich, "Direct patterning of polystyrene-polymethyl methacrylate copolymer by means of laser interference lithography using UV laser irradiation," Polymer Engineering and Science, vol. 48, no. 12, pp. 2367-2372, 2008.

[16] N. Scharnagl and M. Schossig, "Charakterisierung von membranen," Chemie-Ingenieur-Technik, vol. 77, no. 5, pp. 517-526, 2005.

[17] C. A. Schneider, W. S. Rasband, and K. W. Eliceiri, "NIH Image to ImageJ: 25 years of image analysis," Nature Methods, vol. 9, no. 7, pp. 671-675, 2012.

[18] T. Takeuchi, S. Tsuge, and Y. Sugimura, "Near-infrared spectrophotometric analysis of styrene-acrylonitrile copolymer," Journal of Polymer Science Part A-1: Polymer Chemistry, vol. 6, no. 12, pp. 3415-3417, 1968.

[19] K. Arita, T. Ohtomo, and Y. Tsurmi, "Analysis of the monomer sequence distribution in alternating acrylonitrile styrene copolymers by $\mathrm{C}^{13}$-NMR," Journal of Polymer Science: Polymer Letters Edition, vol. 19, pp. 211-216, 1981.

[20] E. Penzel, J. Rieger, and H. A. Schneider, “The glass transition temperature of random copolymers: 1 . Experimental data and the Gordon-Taylor equation," Polymer, vol. 38, no. 2, pp. 325337, 1997.

[21] C. Motta, "The effect of copolymerization on transition temperatures of polymeric materials," Journal of Thermal Analysis, vol. 49, no. 1, pp. 461-464, 1997.

[22] J. A. Brydson, Plastics Materials, Butterworth-Heinemann, Munich, Germany, 5th edition, 1989.

[23] S. Nishio, T. Chiba, A. Matsuzaki, and H. Sato, "Control of structures of deposited polymer films by ablation laser wavelength: polyacrylonitrile at 308, 248, and $193 \mathrm{~nm}$," Journal of Applied Physics, vol. 79, no. 9, pp. 7198-7204, 1996.

[24] N. Grassie and R. McGuchan, "Pyrolysis of polyacrylonitrile and related polymers-I. Thermal analysis of polyacrylonitrile," European Polymer Journal, vol. 6, no. 9, pp. 1277-1291, 1970.

[25] S. Leroy, C. Boiziau, J. Perreau et al., "Molecular structure of an electropolymerized polyacrylonitrile film and its pyroylzed derivatives," Journal of Molecular Structure, vol. 128, no. 4, pp. 269-281, 1985.

[26] M. M. Coleman and R. J. Petcavich, "Fourier transform infrared studies on the thermal degradation of polyacrylonitrile," Journal of Polymer Science Polymer Physics Edition, vol.16, no. 5, pp. 821$832,1978$.

[27] S. Nishio, T. Chiba, A. Matsuzaki, and H. Sato, "Preparation of polymer films by laser ablation of polyacrylonitrile: significant dependence on ablation wavelengths," Applied Surface Science, vol. 106, pp. 132-136, 1996.

[28] W. J. Burlant and J. L. Parsons, "Pyrolysis of polyacrylonitrile," Journal of Polymer Science, vol. 22, no. 101, pp. 249-256, 1956. 
[29] D. F. Acevedo, A. F. Lasagni, M. Cornejo, M. Politano, C. Barbero, and F. Mücklich, "Large area fabrication of tuned polystyrene/poly(methylmethacrylate) periodic structures using laser interference patterning," Langmuir, vol. 25, no. 16, pp. 9624-9628, 2009.

[30] S. Lazare, I. Elaboudi, M. Castillejo, and A. Sionkowska, "Model properties relevant to laser ablation of moderately absorbing polymers," Applied Physics A: Materials Science and Processing, vol. 101, no. 1, pp. 215-224, 2010.

[31] S. A. Saq'an, A. S. Ayesh, A. M. Zihlif, E. Martuscelli, and G. Ragosta, "Physical properties of polystyrene/alum composites," Polymer Testing, vol. 23, no. 7, pp. 739-745, 2004.

[32] A. Lifshitz, M. Bidani, A. Suslensky, and C. Tamburu, "Pyrolysis of acrylonitrile at elevated temperatures. Studies with a singlepulse shock tube," Journal of Physical Chemistry, vol. 93, no. 4, pp. 1369-1373, 1989.

[33] J. H. Hall and M. Gisler, "A simple method for converting nitriles to amides. Hydrolysis with potassium hydroxide in tert-butyl alcohol," The Journal of Organic Chemistry, vol. 41, no. 23, pp. 3769-3770, 1976. 

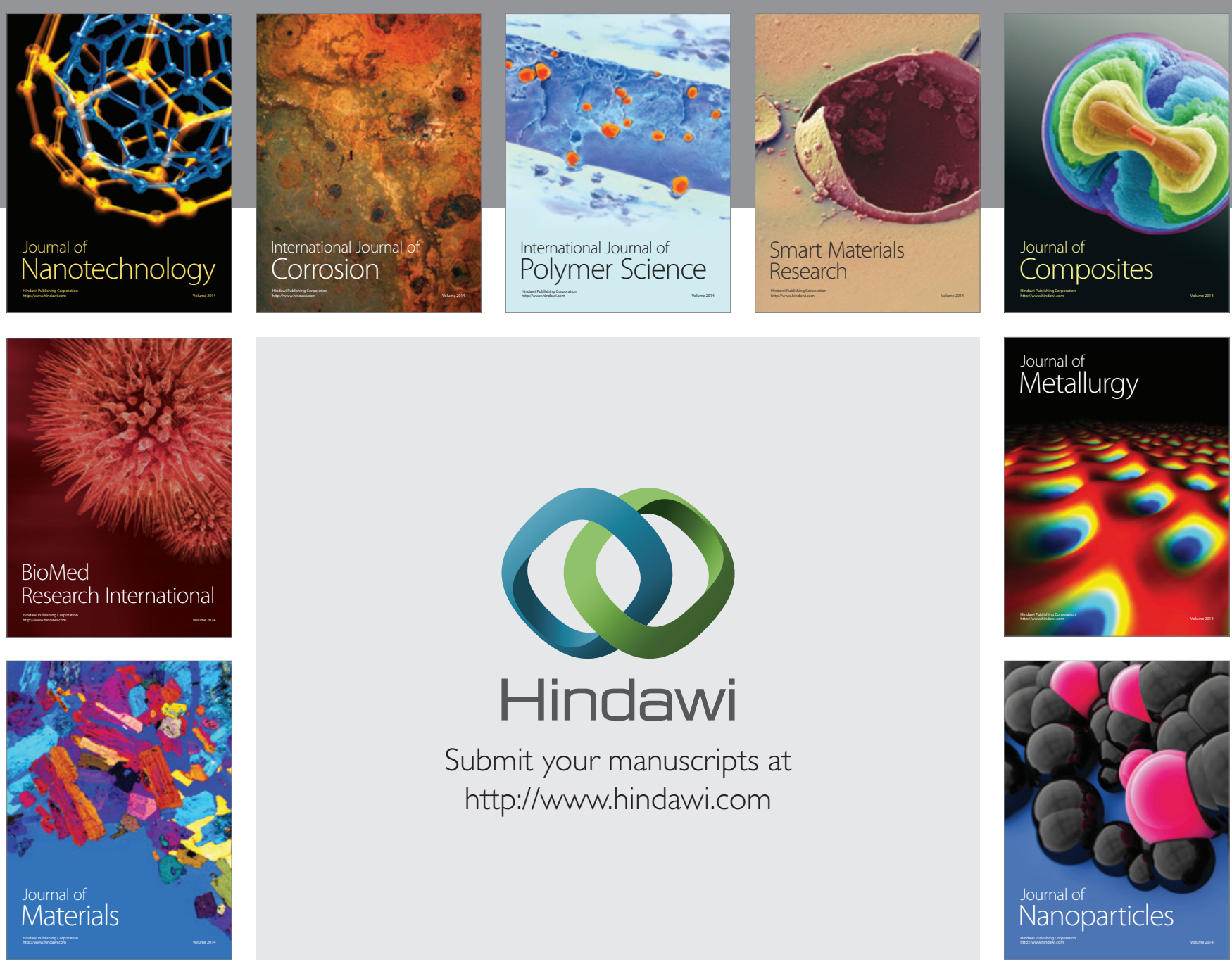

Submit your manuscripts at http://www.hindawi.com
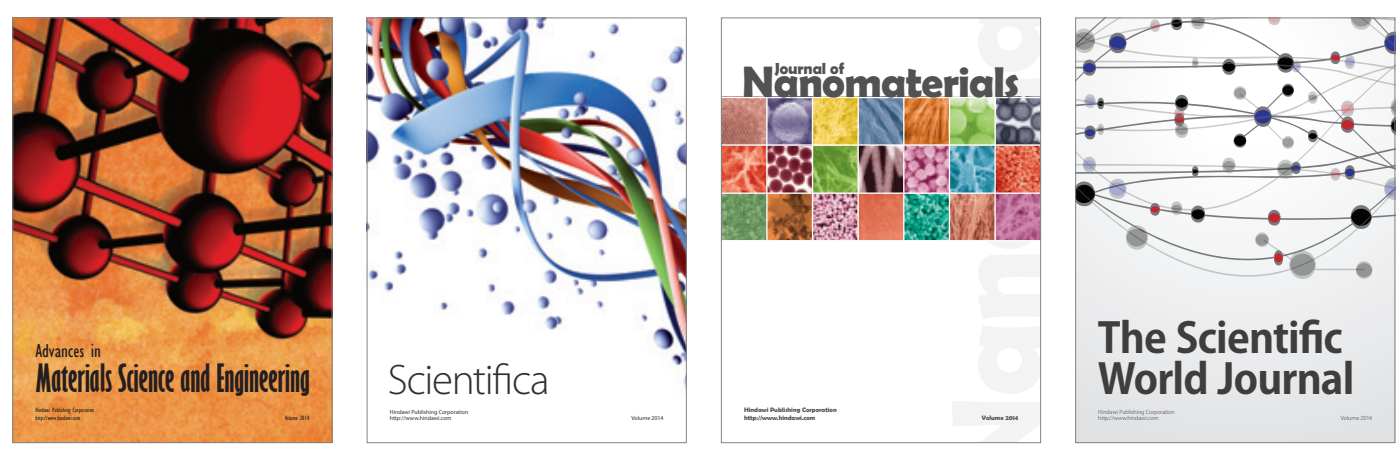

\section{The Scientific World Journal}
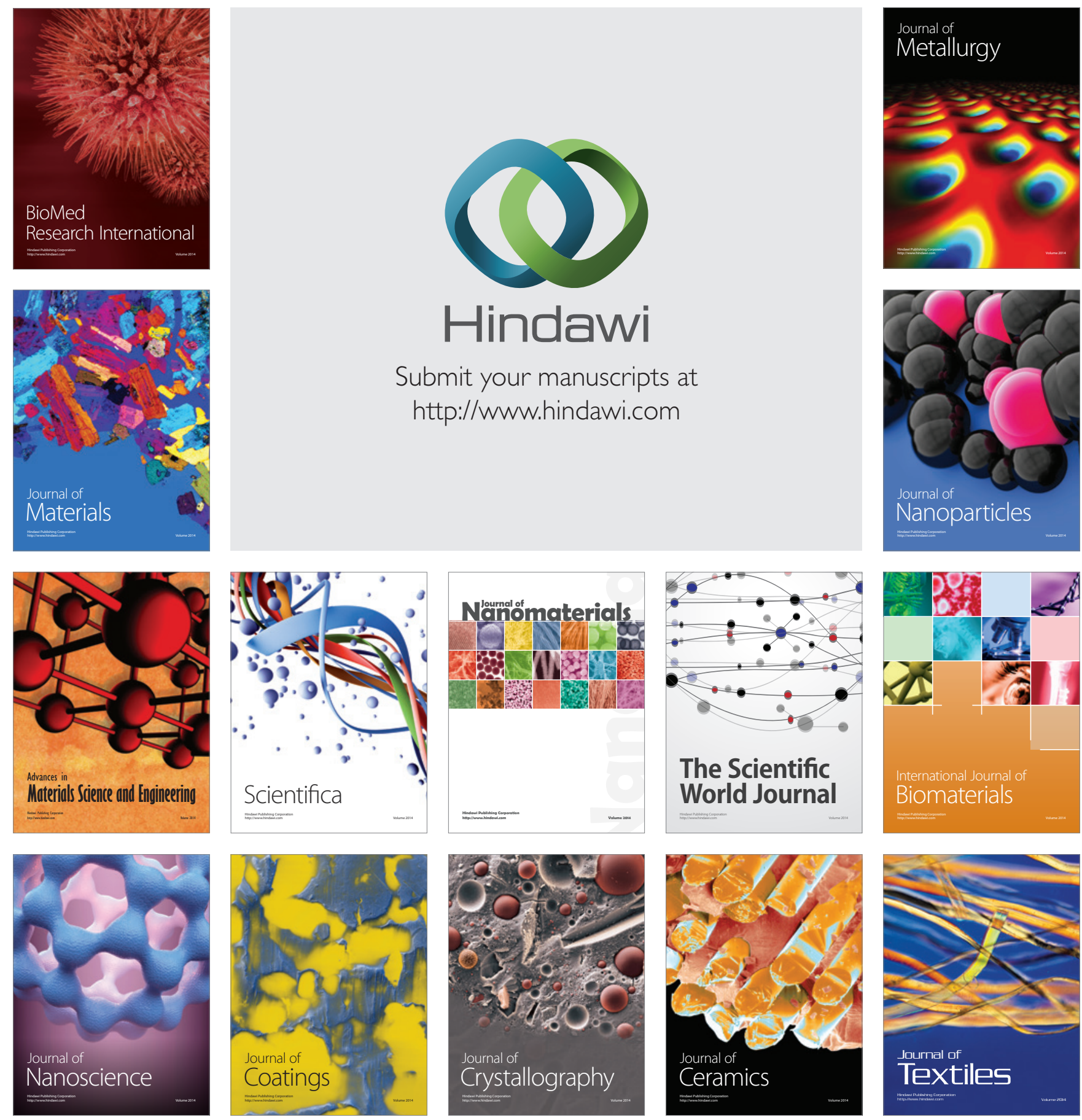